\title{
Long-term assessment of risk factors for canine tumors registered in Xi'an, China
}

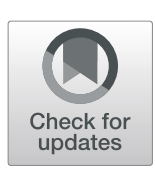

Wei Wang ${ }^{1,2}$, Weihui $\mathrm{Li}^{1,2}$, Dianfeng Chu ${ }^{3,4}$, Jinlian Hua ${ }^{1}$, Xinke Zhang ${ }^{1,2}$, Dezhang $\mathrm{Lu}^{1,2^{*}}$, Yan Wang ${ }^{1 *}$ and Shiqiang Zhang ${ }^{1,2^{*}}$ (D)

\begin{abstract}
Tumors are one of the leading causes to death in pet dogs among diseases. The tumor incidence of pet dogs has been increasing, raising widespread concern. In this study, retrospective analysis was performed with 246 tumor cases registered in Xi'an Animal Hospital, Northwest A\&F University from 2009 to 2018. Correlations of sex, age and breed with tumor incidences were evaluated. The results showed that reproductive system tumors occupied the highest proportion (39.84\%), followed by cutaneous tumors (28.05\%), digestive tumors (18.70\%) and ocular tumor (4.47\%). Among the reproductive system tumors, breast tumors are the most common tumor in female pet dogs, especially for Pekingese (11.43\%). Female dogs with high susceptibility to breast tumors were at the ages of 6-18 years old. As far as cutaneous tumors were concerned, the male pet dogs at all ages, particularly Golden Retrievers (17.39\%), showed a high incidence. By contrast, male Samoyed aged from 4 to 13 years had the highest incidence (15.22\%) of digestive tumors. In addition, pet dogs with ocular tumors mainly happened at the ages of 0-1 years and 6-13 years. Collectively, our findings are significant to develop effective measures of medical surveillance for pet dogs' health and will provide insights for comparative oncology.
\end{abstract}

Keywords: Pet dogs, Tumors, Epidemiological analysis, Risk factors

\section{Main text}

According to the statistics in the white paper on China's pet industry in 2020, the number of pet dogs in China has reached 52.22 million. Tumor has become a common disease in pet dogs. The incidence of tumors on pet dogs varies from 0.282 to $1.701 \%$ (Baioni et al. 2017; M. Vascellari et al. 2016), which have become a serious threat to pet dogs' health. Factors affecting the incidence of pet dog tumors are very complex, including age, breed, diet, living environment and other aspects (Bonnett and Egenvall 2010). Analysis of the epidemiological factors that cause tumorigenesis on pet dogs is particularly necessary to develop effective measures of

\footnotetext{
* Correspondence: dezhanglu@nwsuaf.edu.cn; wangyan11@nwsuaf.edu.cn; shiqiangzhang@nwsuaf.edu.cn

${ }^{1}$ College of Veterinary Medicine, Shaanxi Center of Stem Cells Engineering \& Technology, Northwest A\&F University, Yangling 712100, China

Full list of author information is available at the end of the article
}

medical surveillance for pet dogs' health. In addition, it will be also significant to study the epidemiological factors of pet dogs' tumors for understanding human tumors, since pet dogs and human beings live in similar environments.

In this study, epidemiological analysis of canine tumor cases registered in Xi'an Animal Hospital, Northwest A\&F University from 2009 to 2018 was performed. Among the 7895 clinical cases, there are 246 canine tumor cases (3.18\%), consisting of 106 males and $140 \mathrm{fe-}$ males. The tumors occurred most in the reproductive system (39.84\%), followed by cutaneous system (28.05\%), gastrointestinal system $(18.70 \%)$, ocular system $(4.47 \%)$, respiratory system (1.63\%), and urinary system $(2.85 \%)$ (Fig. 1a). Linear regression analysis showed that the incidence of tumors was increasing from 2009-2018 (Fig. 1b).

(c) The Author(s). 2021, corrected publication 2021. Open Access This article is licensed under a Creative Commons Attribution 4.0 International License, which permits use, sharing, adaptation, distribution and reproduction in any medium or format, as long as you give appropriate credit to the original author(s) and the source, provide a link to the Creative Commons licence, and indicate if changes were made. The images or other third party material in this article are included in the article's Creative Commons licence, unless indicated otherwise in a credit line to the material. If material is not included in the article's Creative Commons licence and your intended use is not permitted by statutory regulation or exceeds the permitted use, you will need to obtain permission directly from the copyright holder. To view a copy of this licence, visit http://creativecommons.org/ licenses/by/4.0/. The Creative Commons Public Domain Dedication waiver (http://creativecommons.org/publicdomain/zero/1. 0/) applies to the data made available in this article, unless otherwise stated in a credit line to the data. 


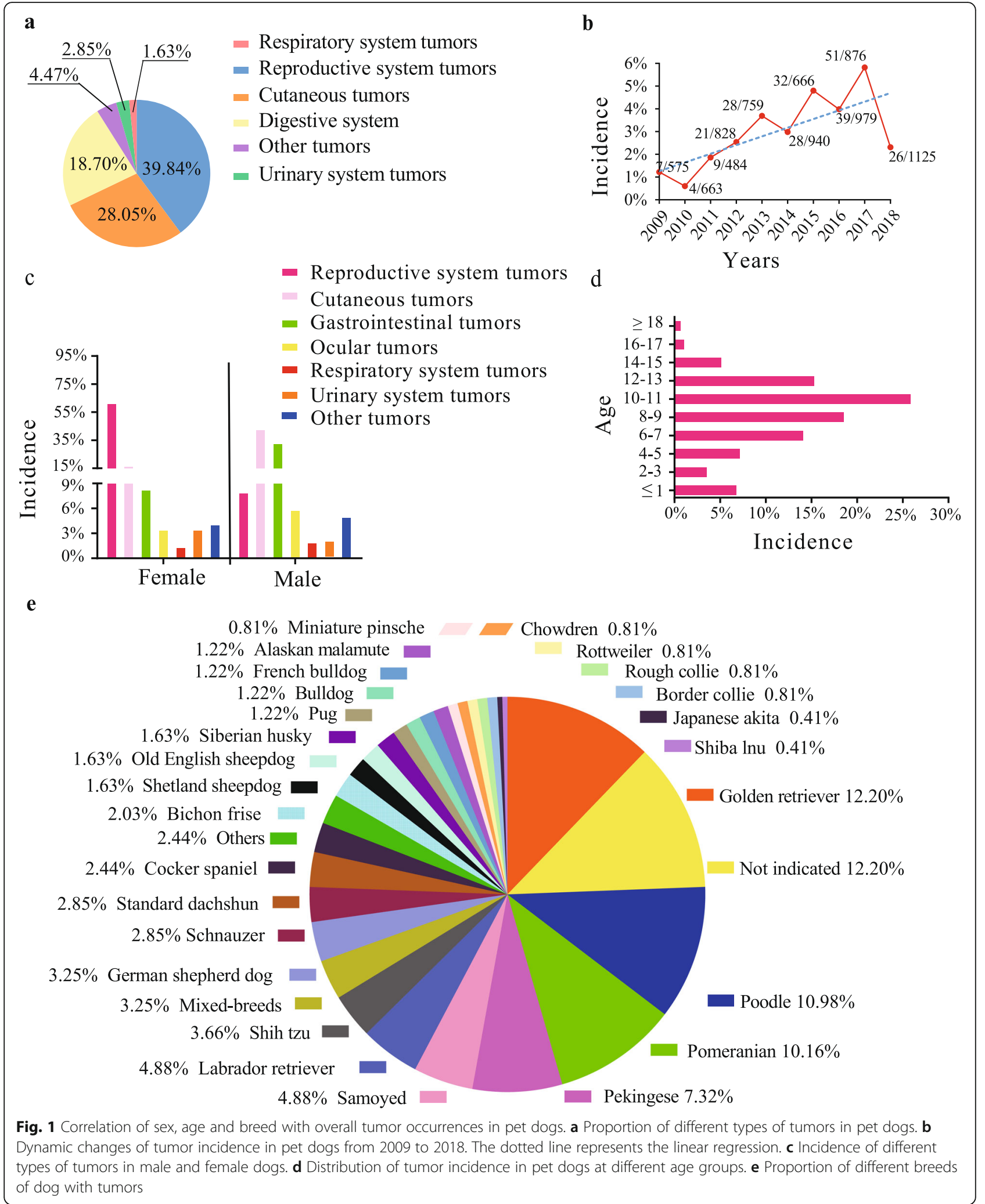


Sex, age and breed are intrinsic risk factors of canine tumors. The most common tumors of female pet dogs were found in the reproductive system (61.81\%). By contrast, the most common tumors of male pet dogs were found in the cutaneous system (43.14\%) (Fig. 1c). The average age of a pet dog with tumor occurrence was 8.8 years. The tumor incidence increased significantly from 6 to 7 years old, peaked at 10 to 11 years old, and decreased after 14 to 15 years old, which may be explained by the dog's life span (Fig. 1d). A total of 34 breeds of pet dogs with tumor occurrence were found during our decade investigation. The tumor occurrence was found most on Golden Retrievers (12.20\%), followed by Poodles (10.98\%), Pomeranian (10.16\%) and Pekingese (7.32\%) (Fig. 1e). Next, it was analyzed in detail the risks of sex, age and breed on tumors of reproductive system, cutaneous system, digestive system, and ocular system.

In our collection of clinical cases, tumors of the reproductive system include breast tumors, vaginal tumors, testicular tumors, and ovarian tumors, among which breast tumors accounted for the largest proportion (71.43\%) (Fig. 2a). During the decade (from 2009 to 2018), the breast tumor occurrence rose steadily. (Fig. 2b). Pekingese (11.43\%), Poodle (10.00\%) and Pomeranian $(10.00 \%)$ were the main breeds with high susceptibility to breast tumor (Fig. 2c). The age distribution of pet dogs with breast tumors ranged from 6 to 18 years old (Fig. 2d). Particularly, the age distribution of Pekingese with breast tumors spanned from 10 to15 years old (Fig. 2e), most had no history of sterilization (87.14\%) (Table S1).

Incidence of cutaneous tumors ranked the second in all pet dogs' tumors cases of this reasearch which kept steady around 30\% (Fig. 3a). Among the 69 cases of cutaneous tumors, 44 males and 25 females were registered, respectively. The average age of the pet dogs with this tumor was 7.3 years. The female pet dogs aged 6-13 were prone to cutaneous tumors. By contrast, male dogs at all ages were vulnerable to cutaneous tumors (Fig. $3 \mathrm{~b})$. When considered breeds together with sex, male Golden Retrievers ranked the highest incidence (17.39\%) in male dogs, followed by male Poodle, and female Poodle (Fig. 3c). Then, age distribution of Golden Retrievers with cutaneous tumors were further accessed. The results showed that Golden Retrievers were susceptible to cutaneous tumors in all ages, particularly with high incidence at 10-11 and 8-9 years old (Fig. 3d).

According to the collected tumor cases, digestive tumors fall into three broad categories: gastrointestinal tumors $(41.30 \%)$, oral tumors $(34.78 \%)$, and liver tumors (23.92\%) (Fig. 4a). There was no significant increase in digestive tumors between 2009 and 2018, keeping incidences around 20\% (Fig. 4b). Conjoint analysis of sex with breeds revealed that male Samoyed had the highest incidence (15.22\%) of digestive tumors (Fig. 4c). Age distribution of male Samoyed spanned from 4 to 13 years old (Fig. 4d) and all male pet dogs at the age of 10-11 had the highest incidence of digestive tumors (Fig. 4e).

There were 11 cases of ocular tumors during this investigation decade, including 6 males and 5 females with no significant sex difference owing to the small size of dataset. A slight upward trend of ocular tumors was observed, but not more than 5\% incidence. (Fig. 5a). The average age of dogs with ocular tumors was 7.5 years, mainly distributed in $0-1$ years and 6-13 years, indicating that the juvenile ocular tumors might be congenital diseases, while the elderly ocular tumors might be aging disease (Fig. 5b). There was no obvious difference on ocular tumors occurrence among breeds (Fig. 5c).

The limitation of this study is that the size of tumor samples is relatively small, including only 10 years of registered cases from Xi'an Animal Hospital, Northwest A\&F University. However, our conclusions are in line with those of other research groups in China (Chen 2015; Qu et al., 2019; He 2020) and abroad (Vascellari et al. 2016). All these studies reveal the prevalence of reproductive system tumors, cutaneous tumors and digestive tumors, although there are regional variations.

The findings of this study will be useful for making effective intervention measures to prevent canine tumorigenesis in the veterinary clinic. Male and female pet dogs differed on some aspects of physiological regulation, especially on endocrine regulation. There is a strong correlation of breast tumor occurrence with high levels of estrogen (Gruntzig et al. 2015). Consistent with previous studies (Dobson 2013; Baioni et al. 2017), this study indicates that female pet dogs over 9 years old are susceptible to breast tumors. This is similar with other research groups (Table S2) (Qu et al., 2019; Chen 2015; Cai 2015; Yan 2013; Chang 2018; Tang 2016; Zhu et al., 2015). Early sterilization or normal mating can be effective in reducing estrogen levels, which in turn reduces the risk of breast tumors (Ferguson 1985; Vascellari et al. 2016; Gundim et al. 2016).

By contrast, male pet dogs over nine years old are vulnerable to cutaneous tumors. Other research with both domestic (Table S3) (Li et al., 2021; Zhu et al., 2015; Yan 2013; Chang 2018) and foreign breeds (Baioni et al. 2017; Merlo et al., 2008; Dobson 2013), support our conclusions. Because sweat gland tumors are associated with androgen, male dogs have a higher incidence rate (Andrade et al., 2010). The high incidence of cutaneous tumors, especially sweat gland tumors on old male pet dogs may be associated with high androgen levels (Andrade et al. 2010; Baioni et al. 2017; Merlo et al. 2008; Dobson 2013). 


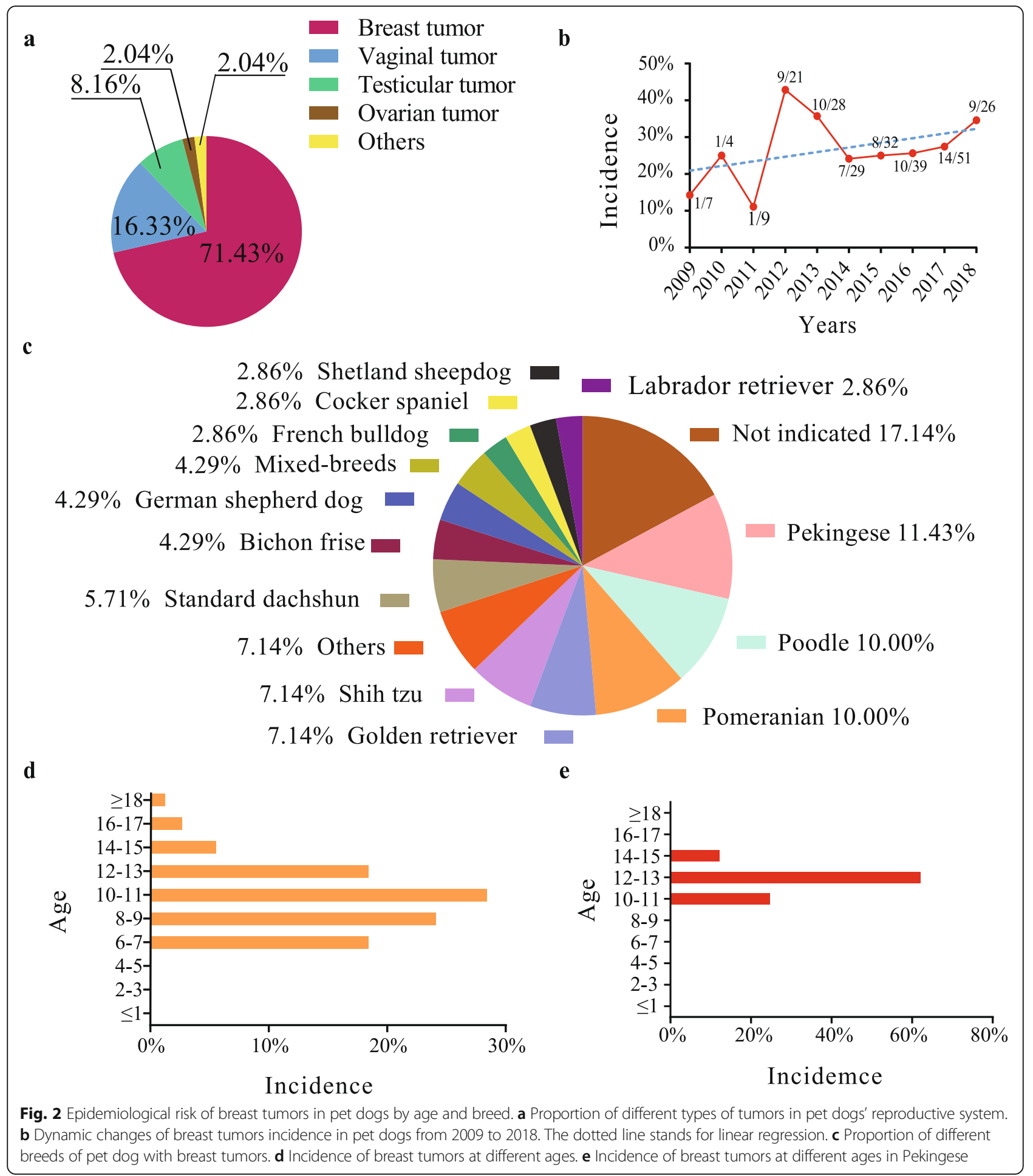

As far as digestive tumors are concerned, it is still unclear why old male pet dogs have a high susceptibility (Brønden, Nielsen, et al., 2010; Patnaik et al. 1977). We speculate that this may be the result of the interactions between sex, dietary factors, genetic factors, immunodeficiency and aging (Graf et al. 2018).
Epidemiological risk of breeds on tumor occurrence suggests Golden Retrievers, Poodles and Pomeranian are prone to tumors, which is consistent with the previous viewpoint that inbred breeds have a higher risk of developing tumors than hybrid breeds (Baioni et al. 2017). Particularly, Golden retrievers are highly 


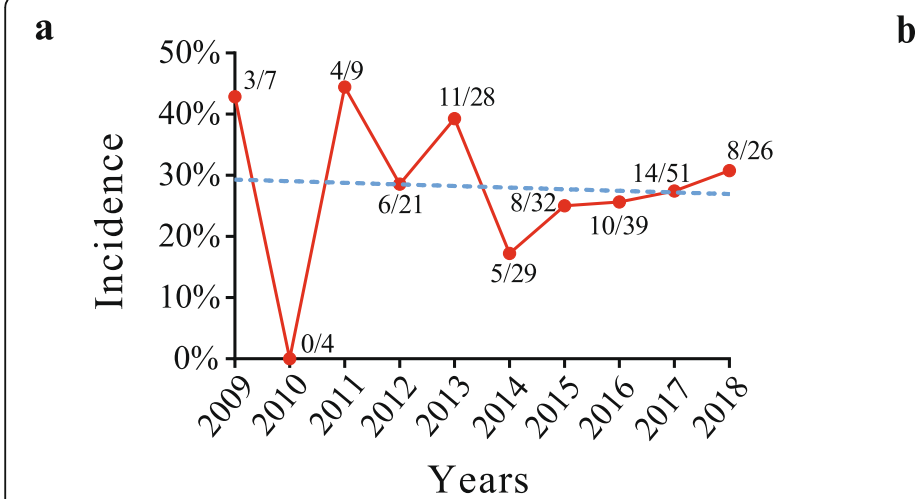

b

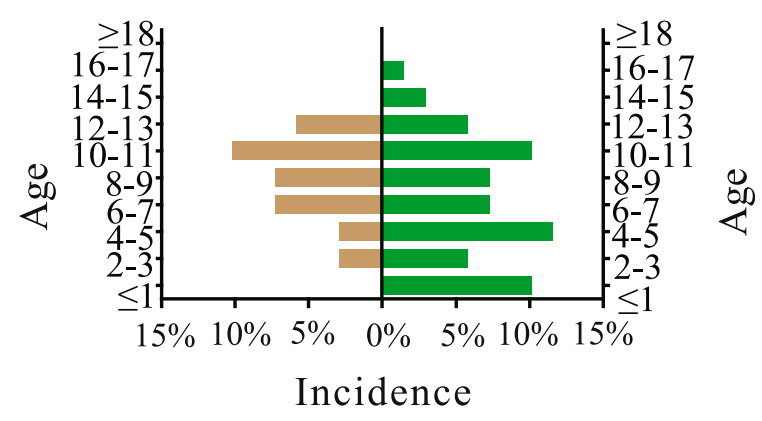

c

Breeds

Not indicated

Old english sheepdog
Border collie

Belaian tervueren

Alaskan malamute

Canis lupus familiaris

Standard dachshun

Shetland sheepdog

Siberian husky

Shih tzu

Pekingese

Cocker spaniel

Schnauzer

Bichon frise

German shepherd dog

Samoyed

Labrador retriever

Golden retriever

Mixed-breeds

Poodle
Pomeranian

$20 \%$

Female

\section{Breeds}

Male

Not indicated

Old english sheepdog

Border collie

Belaian tervueren

Alaskan malamute

Canis lupus familiaris

Standard dachshun

Shetland sheepdog

Siberian husky

- Shih tzu

- Pekingese

- Cocker spaniel

- Schnauzer

Bichon frise

-German shepherd dog

- Samoyed

Labrador retriever

- Golden retriever

Mixed-breeds

Poodle

Pomeranian

$\begin{array}{lllll}0 \% & 5 \% & 10 \% & 15 \% & 20 \%\end{array}$

Incidence

d

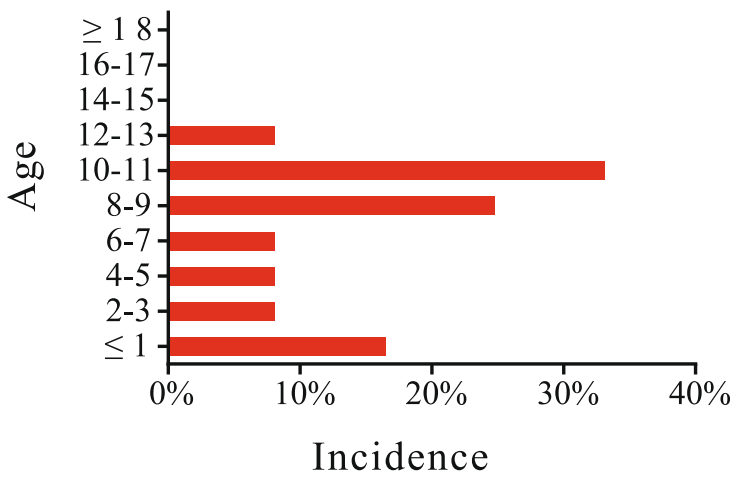

Fig. 3 Correlation of sex, age and breed with cutaneous tumors in pet dogs. a Dynamic changes of cutaneous tumors incidence in pet dogs from 2009 to 2018. The dotted line represents linear regression. b Incidence of cutaneous tumors in male and female pet dogs at different ages. c Incidence of cutaneous tumors in different breeds of male and female pet dogs. $\mathbf{d}$ Incidence of cutaneous tumors in Golden Retrievers at different ages 


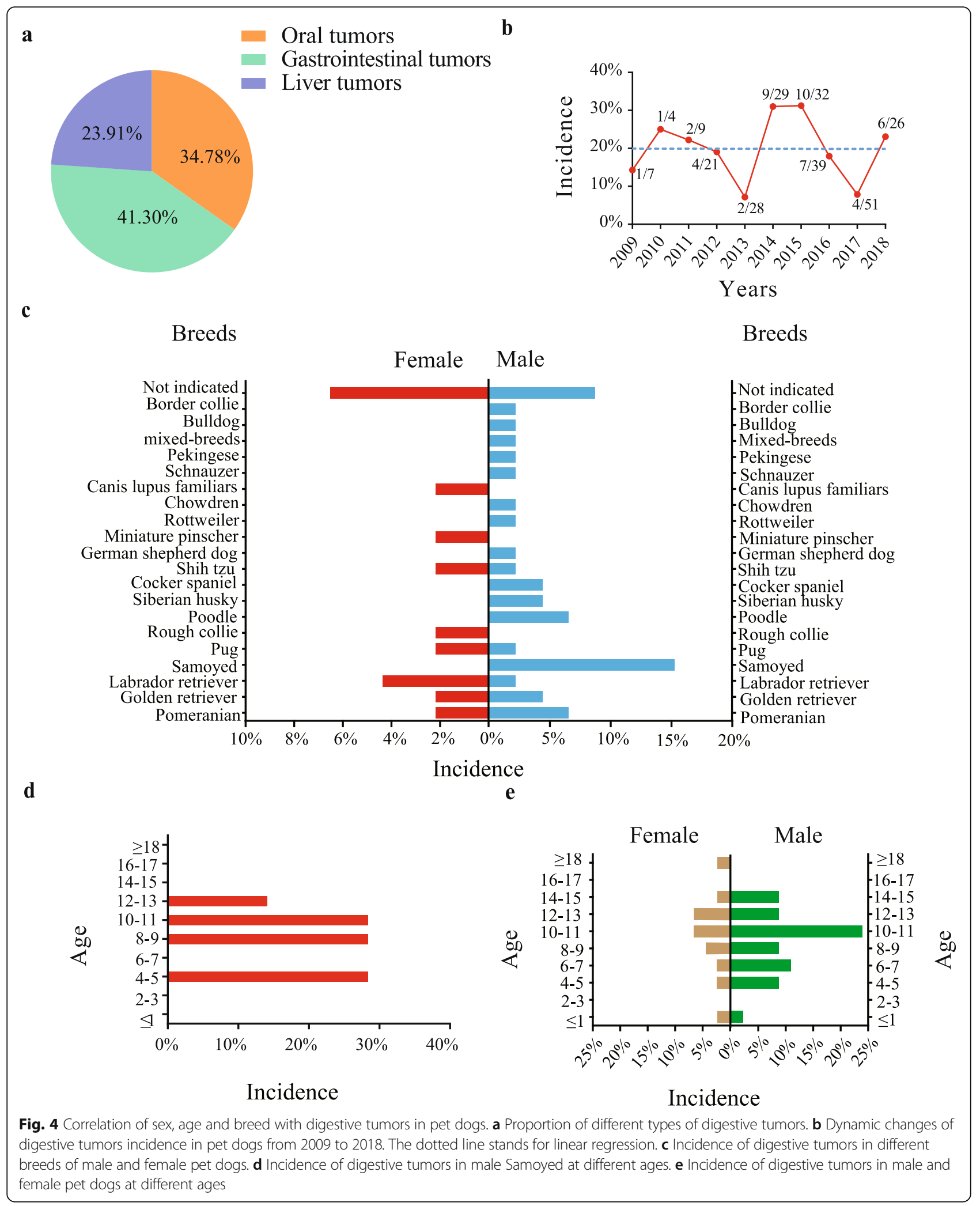


a

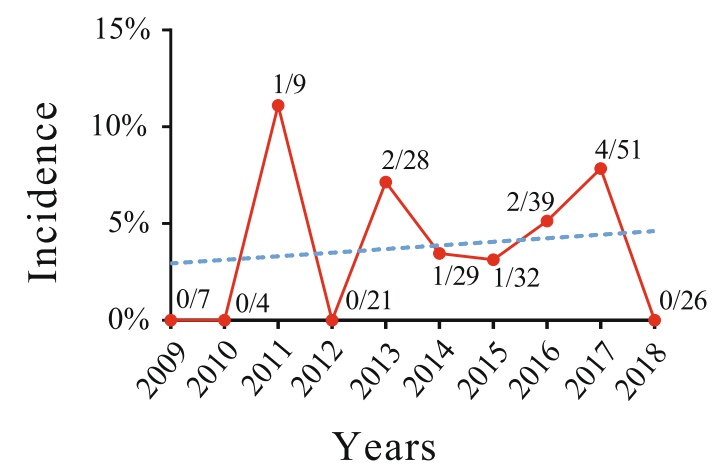

b

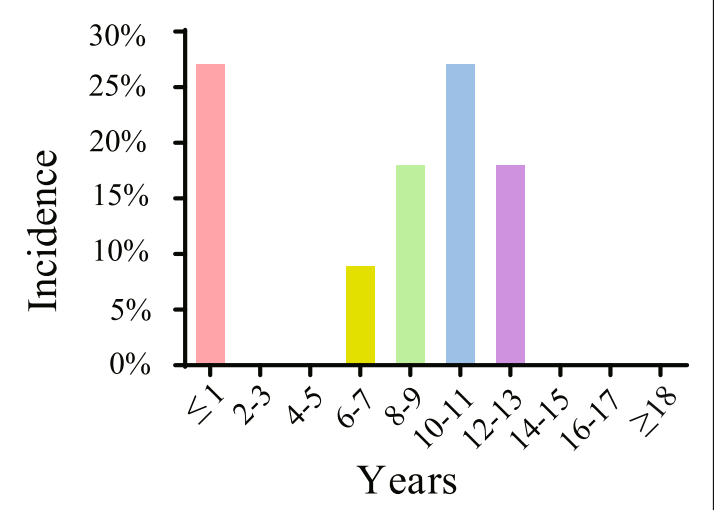

c

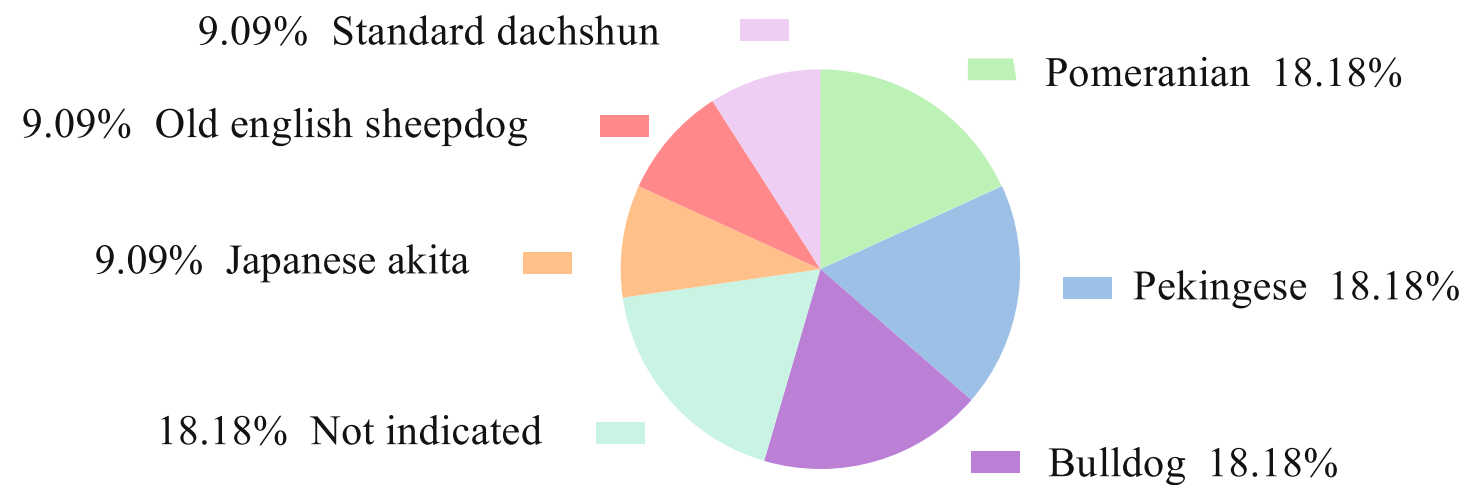

Fig. 5 Correlation of age and breed with ocular tumors in pet dogs. a Dynamic changes of ocular tumors incidence in pet dogs from 2009 to 2018. The dotted line represents linear regression. $\mathbf{b}$ Incidence of ocular tumors in pet dogs at different ages. $\mathbf{c}$ Proportion of different breeds with ocular tumors

susceptible to cutaneous tumors, even at a young age (Graf et al. 2018; Kok et al. 2019). In addition, this research suggests that Pekingese and Samoyed are prone to breast tumors and digestive tumors, respectively. Further studies on different dog breeds prone to a particular tumor will provide insights for the comparative oncology (Wong et al. 2021; Raposo et al. 2017; Vascellari et al. 2016).

\section{Methods}

In this study, the clinical tumor cases registered in Xi'an Animal Hospital, Northwest A\&F University from 2009 to 2018 were manually sorted out and used for retrospective study. The basic information of each clinical tumor case consists of year, breed, sex, age, tumor type and locations (Table S4). The incidences of different types of tumors relative to sex, age and breed were calculated and compared. The linear regression was also performed for tumor incidences and years. GraphPad Prism 8.0 was used for statistical analyses.

\section{Supplementary Information}

The online version contains supplementary material available at https://doi. org/10.1186/s44149-021-00032-6.

Additional file 1: Table S1.

Additional file 2: Table S2.

Additional file 3: Table S3.

Additional file 4: Table S4.

\section{Acknowledgements}

We would like to thank the members of Shaanxi Center of Stem Cells Engineering \& Technology for helpful discussions.

\section{Authors' contributions}

Z.S., W.Y. and L.D. contributed to the conception, design of this work and supervised the research; W.W, L.W. and Z.S. drafted the manuscript; H.J., C.D. and Z.X. revised the manuscript and provided intellectual input; L.D. and Z.X. provide case data; W.W. and L.W. participated in sample collection and data analysis. All authors have read and approved the final version of the manuscript.

\section{Funding}

This research was funded by grants from the Xi'an Northwest Agriculture and Forestry University Animal Hospital Co., Ltd. (K4040121234), the State Key Laboratory of Genetically Engineered Veterinary Vaccines (AGVSKL-ZY- 
201802, AGVSKL-ZD-202009), and the NWAFU Fundamental Research Funds for the Central Universities (2452019055).

\section{Availability of data and materials}

Data will be shared upon request by the readers.

\section{Declarations}

Ethics approval and consent to participate

Not applicable.

\section{Consent for publication}

Not applicable.

\section{Competing interests}

The authors declare no competing or financial interests.

\section{Author details}

'College of Veterinary Medicine, Shaanxi Center of Stem Cells Engineering \& Technology, Northwest A\&F University, Yangling 712100, China. ${ }^{2}$ Xi'an Animal Hospital, Northwest A\&F University, Yangling 712100, China. ${ }^{3}$ Yebio Bioengineering Co., Ltd of Qingdao, Qingdao 266000, China. ${ }^{4}$ State Key Laboratory of Genetically Engineered Veterinary Vaccines, Shandong 266114, China.

Received: 18 July 2021 Accepted: 15 November 2021

Published online: 29 November 2021

\section{References}

Andrade, F.H., F.C. Figueiroa, P.R. Bersano, D.Z. Bissacot, and N.S. Rocha. 2010. Malignant mammary tumor in female dogs: Environmental contaminants. Diagnostic Pathology 5 (1): 45. https://doi.org/10.1186/1746-1596-5-45.

Baioni, E., E. Scanziani, M.C. Vincenti, M. Leschiera, E. Bozzetta, M. Pezzolato, R. Desiato, S. Bertolini, C. Maurella, and G. Ru. 2017. Estimating canine cancer incidence: Findings from a population-based tumour registry in northwestern Italy. BMC Veterinary Research 13 (1): 203. https://doi.org/10.11 86/s12917-017-1126-0

Bonnett, B.N., and A. Egenvall. 2010. Age patterns of disease and death in insured Swedish dogs, cats and horses. Journal of Comparative Pathology 142 (Suppl 1): S33-S38. https://doi.org/10.1016/j.jcpa.2009.10.008.

Brønden, L.B., S.S. Nielsen, N. Toft, and A.T. Kristensen. 2010. Data from the Danish veterinary cancer registry on the occurrence and distribution of neoplasms in dogs in Denmark. Veterinary Record 166 (19): 586-590. https://doi.org/1 $0.1136 / v r . b 4808$.

Cai, X. 2015. Study on the epidemiologieal investigations diagnosis and treatment of canine Mammary tumors in baoding region. Hebei: Hebei Agricultural University.

Chang, H. 2018. Epidemiology analysis of 271 cases tumor in canines and Screeningor screening of serum/tissue markers for canine. Hongjian, Northeast Agricultural University.

Chen, L. 2015. Clinical diagnosis of common neoplastic diseases indogs. Jiangsu: Yangzhou University.

Dobson, J.M. 2013. Breed-predispositions to cancer in pedigree dogs. ISRN Veterinary Science 2013: 1-23. https://doi.org/10.1155/2013/941275.

Ferguson, H. R. 1985. Canine mammary gland tumors. The Veterinary clinics of North America. Small animal practice 15(3):501-511. https://doi.org/10.1016/ s0195-5616(85)50053-4.

Graf, R., A. Pospischil, F. Guscetti, D. Meier, M. Welle, and M. Dettwiler. 2018. Cutaneous tumors in Swiss dogs: Retrospective data from the Swiss canine Cancer registry, 2008-2013. Veterinary Pathology 55 (6): 809-820. https://doi. org/10.1177/0300985818789466.

Grüntzig, K., R. Graf, M. Hässig, M. Welle, D. Meier, G. Lott, D. Erni, N.S. Schenker, F. Guscetti, G. Boo, K. Axhausen, S. Fabrikant, G. Folkers, and A. Pospischil. 2015. The Swiss canine Cancer registry: A retrospective study on the occurrence of tumours in dogs in Switzerland from 1955 to 2008. Journal of Comparative Pathology 152 (2-3): 161-171. https://doi.org/10.1016/j.jcpa.2015.02.005.

Gundim, L.F., C.P. de Araújo, W.T. Blanca, E.C. Guimarães, and A.A. Medeiros. 2016. Clinical staging for bitches with mammary tumors: Influence of type and histological grade. Canadian Journal of Veterinary Research 80 (4): 318-322.

He, S. 2020. An Investigation and Case Analysis of Dog Tumor Disease in Chaoyang District of Beijing. Xinjiang: Xinjiang Agricultural University.
Kok, M.K., J.K. Chambers, M. Tsuboi, R. Nishimura, H. Tsujimoto, K. Uchida, and H. Nakayama. 2019. Retrospective study of canine cutaneous tumors in Japan, 2008-2017. Journal of Veterinary Medical Science 81 (8): 1133-1143. https://doi. org/10.1292/jvms.19-0248.

Li, Z., X. Zhang, and M. Zhu. 2021. Analysis of canine tumor cases in Kunming. Chinese Journal of Veterinary Medicine 57 (3): 67-69.

Merlo, D.F., L. Rossi, C. Pellegrino, M. Ceppi, U. Cardellino, C. Capurro, A. Ratto, P.L. Sambucco, V. Sestito, G. Tanara, and V. Bocchini. 2008. Cancer incidence in pet dogs: Findings of the animal tumor registry of Genoa, Italy. Journal of Veterinary Internal Medicine 22 (4): 976-984. https://doi.org/10.1111/j.1939-1 676.2008.0133x

Patnaik, A.K., A.I. Hurvitz, and G.F. Johnson. 1977. Canine gastrointestinal neoplasms. Veterinary Pathology 14 (6): 547-555. https://doi.org/10.1177/03 0098587701400602

Qu, G., T. Yang, and B. Yin. 2019. Investigation and analysis on the incidence of canine tumor diseases in Jilin area. Jilin Animal Husbandry and Veterinary 40 (12): 7-9.

Raposo, T.P., H. Arias-Pulido, N. Chaher, S.N. Fiering, D.J. Argyle, J. Prada, I. Pires, and F.L. Queiroga. 2017. Comparative aspects of canine and human inflammatory breast cancer. Seminars in Oncology 44 (4): 288-300. https://doi. org/10.1053/j.seminoncol.2017.10.012.

Tang, W. 2016. Investigation and clinical case study of canine breast tumors in Nanjing. Jiangsu: Nanjing Agricultural University.

Vascellari, M., K. Capello, A. Carminato, C. Zanardello, E. Baioni, and F. Mutinelli. 2016. Incidence of mammary tumors in the canine population living in the Veneto region (Northeastern Italy): Risk factors and similarities to human breast cancer. Preventive Veterinary Medicine 126: 183-189. https://doi.org/10.1 016/j.prevetmed.2016.02.008.

Wong, K., L. Ludwig, O. Krijgsman, D.J. Adams, G.A. Wood, and L. van der Weyden. 2021. Cross-species comparison of the endogenetic landscape of canine and feline hemangiosarcoma shows novel parallels with human angiosarcoma. Disease Models \& Mechanisms 14 (7). https://doi.org/10.1242/ dmm.049044.

Yan, N. 2013. Epidemiological investigation and research of clinical diagnosis technique of canine tumors in Hefei. Anhui Agricultural University. https:// kns.cnki.net/KCMS/detail/detail.aspx?dbname.

Zhu, G., F. Shi, and Y. Yang. 2015. Investigation on pet dog tumor in Hangzhou from 2012 to 2014. Advances in Animal Medicine 133 (11): 129-132.

\section{Publisher's Note}

Springer Nature remains neutral with regard to jurisdictional claims in published maps and institutional affiliations.

\section{Ready to submit your research? Choose BMC and benefit from:}

- fast, convenient online submission

- thorough peer review by experienced researchers in your field

- rapid publication on acceptance

- support for research data, including large and complex data types

- gold Open Access which fosters wider collaboration and increased citations

- maximum visibility for your research: over $100 \mathrm{M}$ website views per year

At $\mathrm{BMC}$, research is always in progress.

Learn more biomedcentral.com/submission 